\title{
Final Optics Protection in Laser Inertial Fusion with Cryogenic Liquid Droplets
}

\author{
R.W. Moir
}

August 31, 2000

U.S. Department of Energy

Lawrence

Livermore

National

Laboratory 


\section{DISCLAIMER}

This document was prepared as an account of work sponsored by an agency of the United States Government. Neither the United States Government nor the University of California nor any of their employees, makes any warranty, express or implied, or assumes any legal liability or responsibility for the accuracy, completeness, or usefulness of any information, apparatus, product, or process disclosed, or represents that its use would not infringe privately owned rights. Reference herein to any specific commercial product, process, or service by trade name, trademark, manufacturer, or otherwise, does not necessarily constitute or imply its endorsement, recommendation, or favoring by the United States Government or the University of California. The views and opinions of authors expressed herein do not necessarily state or reflect those of the United States Government or the University of California, and shall not be used for advertising or product endorsement purposes.

This work was performed under the auspices of the U.S. Department of Energy by the University of California, Lawrence Livermore National Laboratory under Contract No. W-7405-Eng-48.

This report has been reproduced

directly from the best available copy.

Available to DOE and DOE contractors from the Office of Scientific and Technical Information

P.O. Box 62, Oak Ridge, TN 37831

Prices available from (423) 576-8401

http://apollo.osti.gov/bridge/

Available to the public from the

National Technical Information Service

U.S. Department of Commerce

5285 Port Royal Rd.,

Springfield, VA 22161

http://www.ntis.gov/

OR

Lawrence Livermore National Laboratory

Technical Information Department's Digital Library

http://www.llnl.gov/tid/Library.html 


\title{
FINAL OPTICS PROTECTION IN LASER INERTIAL FUSION \\ WITH CRYOGENIC LIQUID DROPLETS
}

\author{
R. W. Moir
}

August 31, 2000

\begin{abstract}
A burst of $x$ rays and vaporized debris from high yield targets can damage the final optics in laser inertial fusion energy (IFE) power plants and in laboratory experimental facilities such as the National Ignition Facility (NIF) or Laser MegaJoule (LMJ). Noble gases such as Xe or Kr have been proposed to protect final optics from target-produced $x$ rays and debris. Some problems with the use of such ambient gas fills are the large amount of gas involved, heat transfer to a cryogenic target, potential resonant reradiation of $x$ rays absorbed, and a nonuniform index of refraction due to turbulence interfering with the focusing of laser light. Also the fast igniter laser intensity may be too great for propagation through an ambient gas. We propose to provide the gas in the form of many small closely spaced liquid droplets injected in front of the optics. In the case of NIF, the droplets would be injected only when needed just before a high yield shot. The laser light that is absorbed will cause evaporation of the liquid and spreading of this gas. The liquid droplets intercept only $\sim 5 \%$ of the laser light allowing $\sim 95 \%$ to pass through to the target. The light absorbed in the NIF example (assumed to be $50 \%$ of the intercepted light, whose intensity is $3.6 \times 10^{9}$ $\mathrm{W} / \mathrm{cm}^{2}$ ) would cause the xenon droplets to evaporate and spread uniformly such that the $x$ rays from $10 \mathrm{eV}$ to $2 \mathrm{keV}$ are appreciably attenuated when they arrive 40 to $70 \mathrm{~ns}$ later at the optical surface. $X$ rays above $3 \mathrm{keV}$ and below $10 \mathrm{eV}$ are not attenuated very much but their intensities are rapidly falling off in this range
\end{abstract}


anyway. Typical droplet sizes are $\sim 10 \mu \mathrm{m}$ radius with a spacing of $\sim 0.4 \mathrm{~mm}$. The gas would also protect vaporized target debris from condensing on the optics

due to the $0.2 \mathrm{mg} / \mathrm{cm}^{2}$ of xenon $\left(5 \times 10^{17} \mathrm{~cm}^{-2}\right.$ or 8 Torr- $\mathrm{cm}$ for 1-e-folding of $1 \mathrm{keV}$ $\mathrm{x}$-rays). These droplets might be produced with technology similar to ink jet technology and photo-etching of silicon to make nozzle plates. The xenon would be easily pumped away from the chamber. The vapor pressure from the evaporating droplets needs to be studied to see if the laser beam will be disturbed. We recommend further analysis and experimental investigation of this new idea.

\section{Introduction}

Noble gases such as $\mathrm{Xe}$ and $\mathrm{Kr}$ have been proposed to protect final optics from target-produced $x$ rays. Some problems with the use of such ambient gas fills are the large amount of gas involved, heat transfer to a cryogenic target, potential resonant reradiation of $\mathrm{x}$ rays absorbed, and a non-uniform index of refraction due to turbulence interfering with the focusing of laser light. Also the fast igniter laser intensity may be too great for propagation through an ambient gas. These problems can be mitigated by our proposal ${ }^{1}$ to provide the gas in the form of many small closely spaced liquid droplets injected in front of the optics as shown in Fig. 1. The laser light that is absorbed will cause evaporation and spreading of the gas. The optics to be protected in NIF as shown in Fig. 2 are located $7.3 \mathrm{~m}$ from the shot, and those in a conceptual power plant optics system ${ }^{2}$ are located 20 to $30 \mathrm{~m}$ away as shown in Fig. 3. This method of providing the gas is expected to be compatible with the use of fast ignition if the vapor density near the droplets is not too great. 


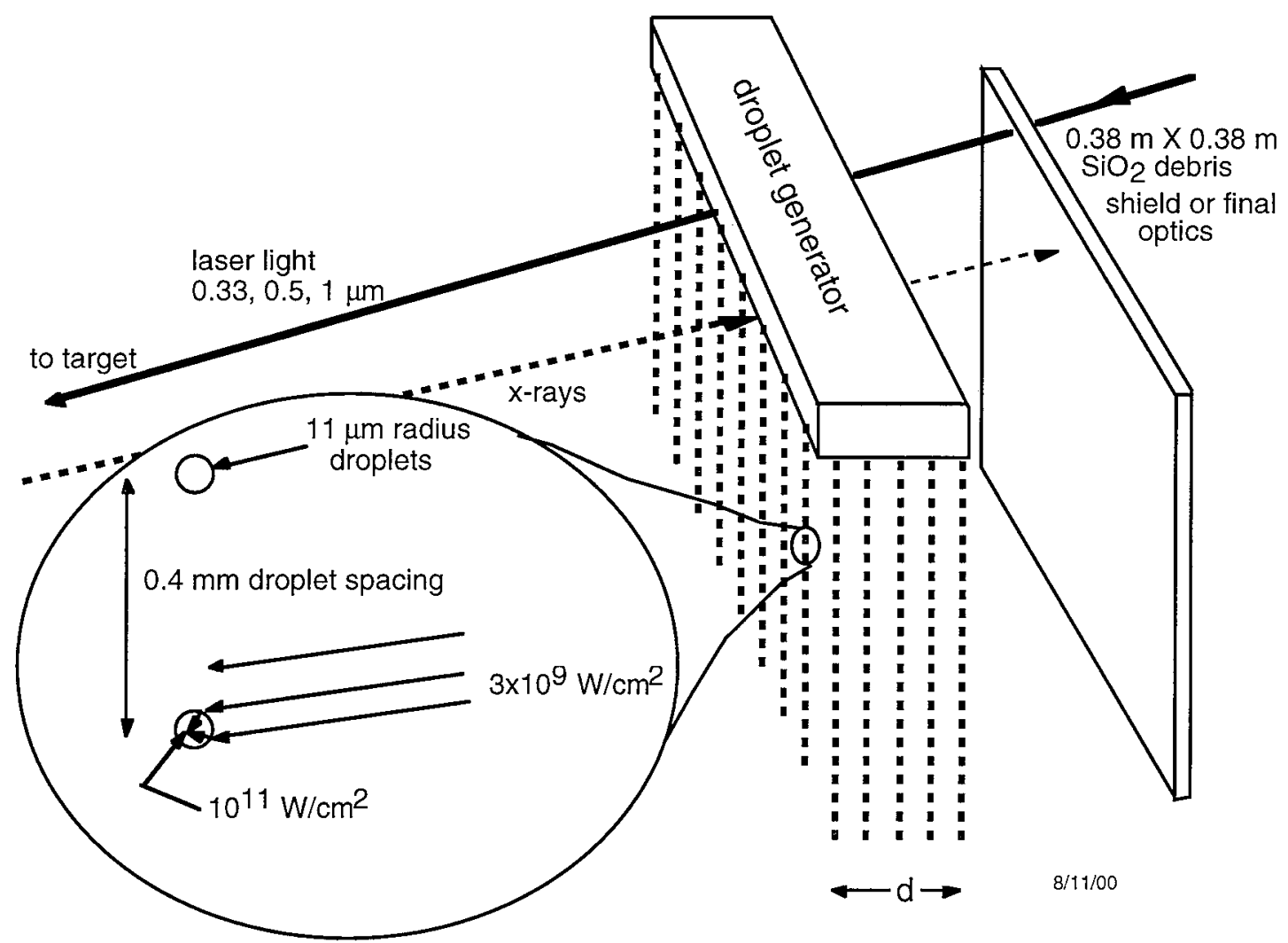

Fig. 1. Pulsed xenon or krypton droplet generator produces a cloud of droplets that lets $95 \%$ of laser light to pass but expands as a gas that stops emitted $x$ rays that might damage the optics in the NIF or a power plant. 


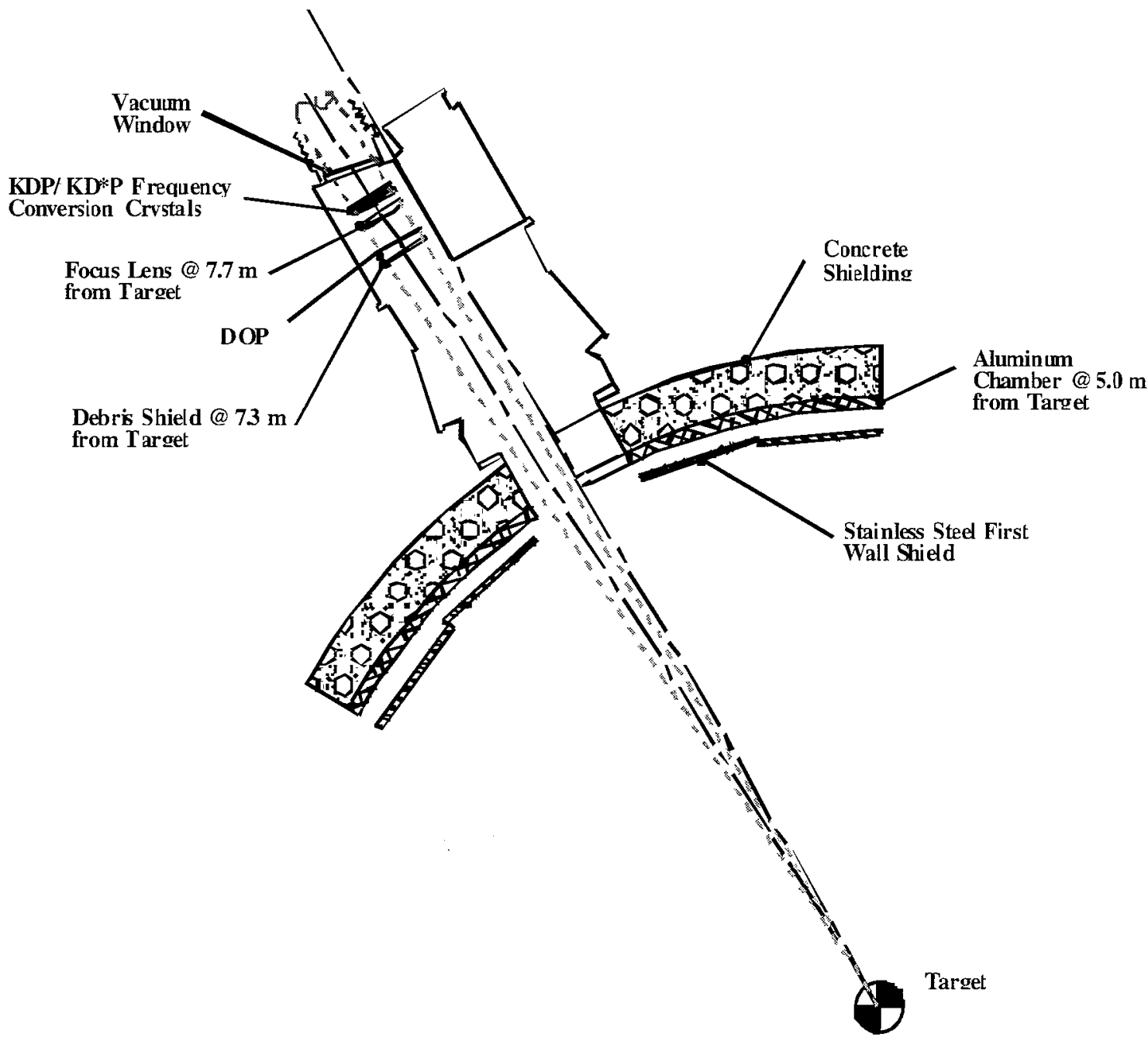

Fig. 2. Final optics for NIF showing the debris shields located at $7.3 \mathrm{~m}$ which are vulnerable to $x$-ray damage. Earlier the debris shield was shown at $6.75 \mathrm{~m}$, which is the number used in this report. 


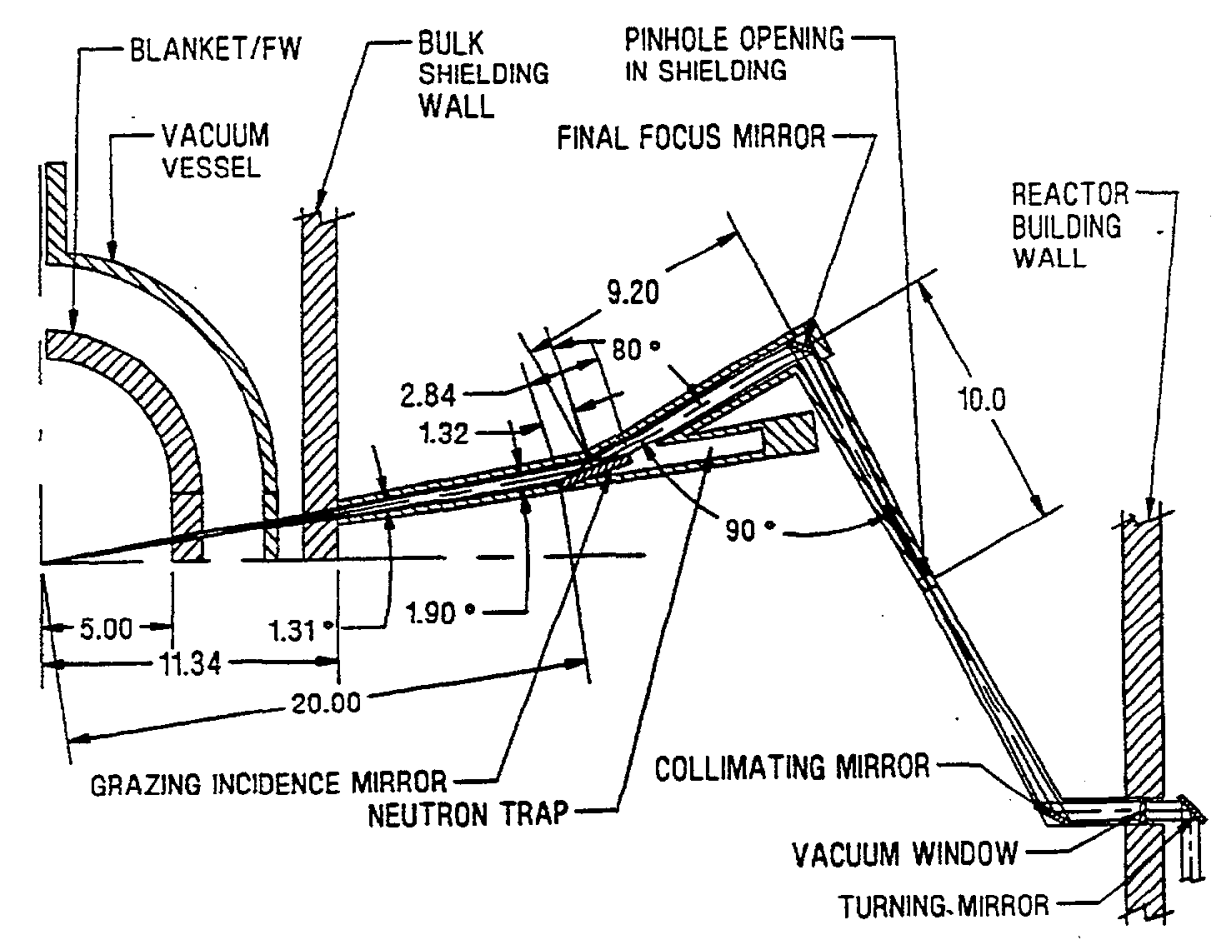

Fig. 3. Final optical elements in the Prometheus ${ }^{2}$ laser inertial fusion energy power plant design with the final optics at $20 \mathrm{~m}$. Other designs commonly use $30 \mathrm{~m}$ stand-off distance to the final optics. Distances are shown in meters.

\section{Assumptions}

We assume the droplet absorption of laser light can be effective and uniform enough so that half of the laser light incident on the droplet goes into kinetic energy. Calculations ${ }^{3}$ show focusing of the $3.6 \times 10^{9} \mathrm{~W} / \mathrm{cm}^{2}$ laser light by two orders of magnitude for $\sim 5 \mu \mathrm{m}$ dia. droplets through refraction at the surface of the cryogenic droplets. Intensities in the range of $10^{11} \mathrm{~W} / \mathrm{cm}^{2}$ should result in strong absorption due to multiple photon interactions. At low intensity, where absorption is essentially nil, a molecular species such as $\mathrm{CH}_{4}$ can be added to the liquid Xe to provide enough absorption to get the process started if needed ${ }^{4}$. If the droplets convert half of the incident laser light into heat $(\sim 2 \mathrm{eV} / \mathrm{Xe}$ atom), this is enough thermal energy to adequately fill the inter-droplet spacing before 
the $\mathrm{x}$-ray burst arrives $42 \mathrm{~ns}$ later. Complete filling of the inter-droplet space is overly conservative and corrections are given later in this paper.

Timing issues include the following. For the NIF (or power plant) cases, the optics protection system is located $0.75 \mathrm{~m}(>1 \mathrm{~m})$ away from the optics, which are $6.75 \mathrm{~m}(30 \mathrm{~m})$ from the target, so the two way light transit time is $40 \mathrm{~ns}$ (200 ns). With a larger stand-off distance ( $30 \mathrm{~m}$ rather than $6.75 \mathrm{~m}$ ), the droplets can be spaced further apart and still the vapor will fill the space due to the longer time. Some examples such as Fig. 3 use a 20-m standoff distance. To avoid a gas pulse on the optics when using larger spacings, the droplets must be injected at a greater distance from the optics. The 1 to 2-ns difference in target implosion time is not significant, nor are the minor differences in target details (NIF vs power plant). More significant is the 17-ns low-intensity laser pre-pulse and the 40-ns spread in emitted $x$ rays. Another factor is not to overheat the droplets. It would be reasonable to heat up the droplets to at most a few $\mathrm{eV}$ per atom. Higher energy would waste much of the energy in ionization and radiation.

The x-ray attenuation cross sections for xenon and krypton are given in Fig. 4. The line density of gas needed to attenuate $x$ rays by one e-folding is plotted in Fig. 5 versus energy. The spectrum of a typical x-ray pulse on the final optics is given in Fig. 6. This case is called, "20 MJ yield, laser entrance hole (LEH) open." " Note the attenuation provided in Fig. 6 is the attenuated $x$ ray pulse on the final optics with two example cases of gas protection for a line density of $4.9 \times 10^{17} / \mathrm{cm} 2$ for $\mathrm{Kr}$ or $\mathrm{Xe}$. As can be seen there is an appreciable decrease in the $\mathrm{x}$ rays striking the optics when droplets are employed. It is obvious that a mixture of $\mathrm{Kr}$ along with the Xe might attenuate the $\mathrm{x}$ rays better between 100 


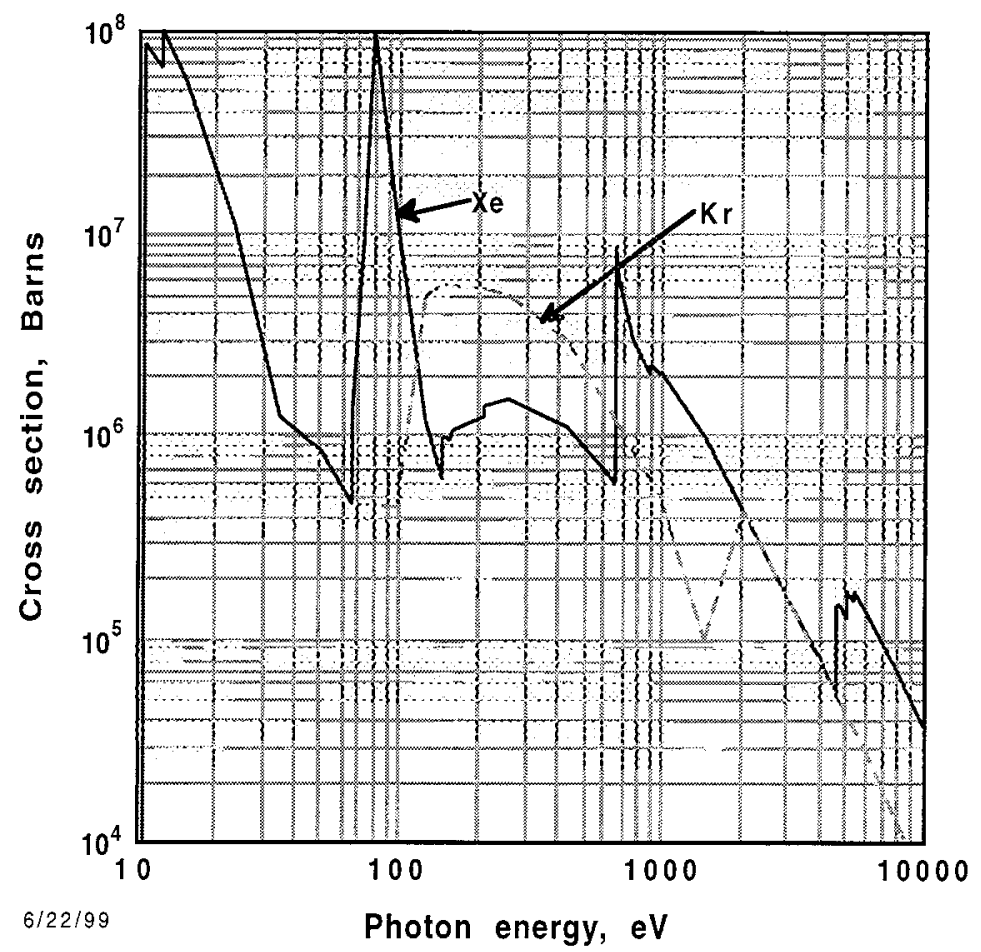

Fig. 4. Absorption cross-section for xenon and krypton versus photon energy.

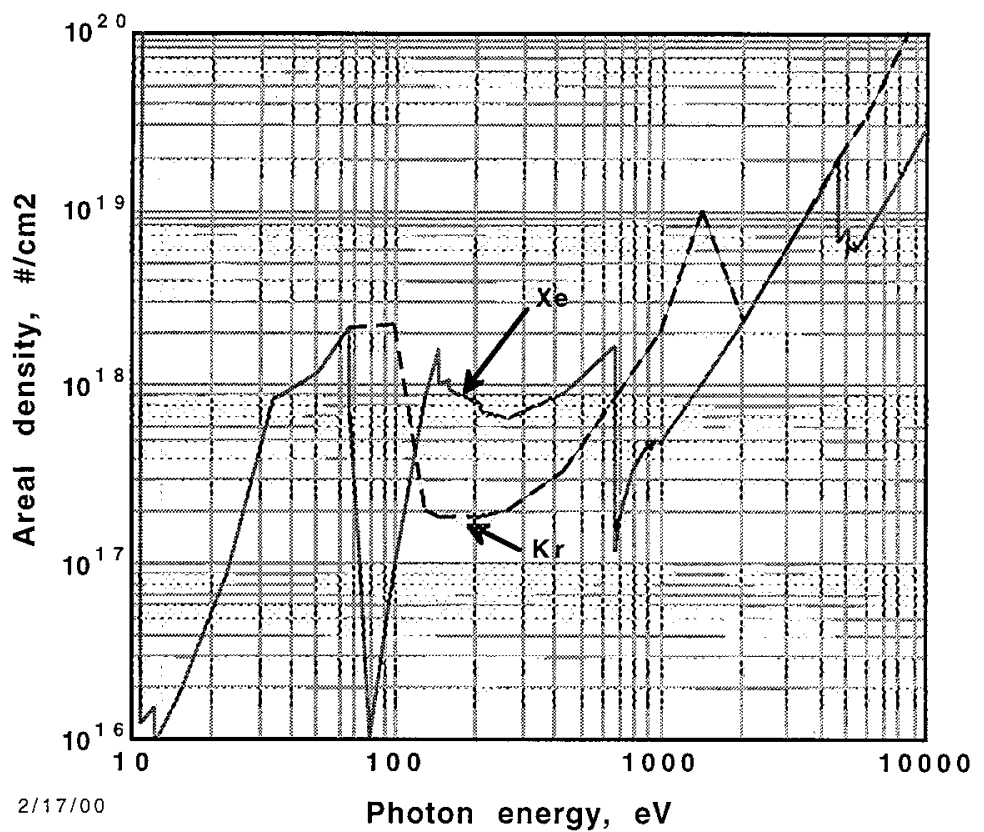

Fig. 5. Areal density for xenon and krypton versus photon energy for one efolding of $x$ rays. 


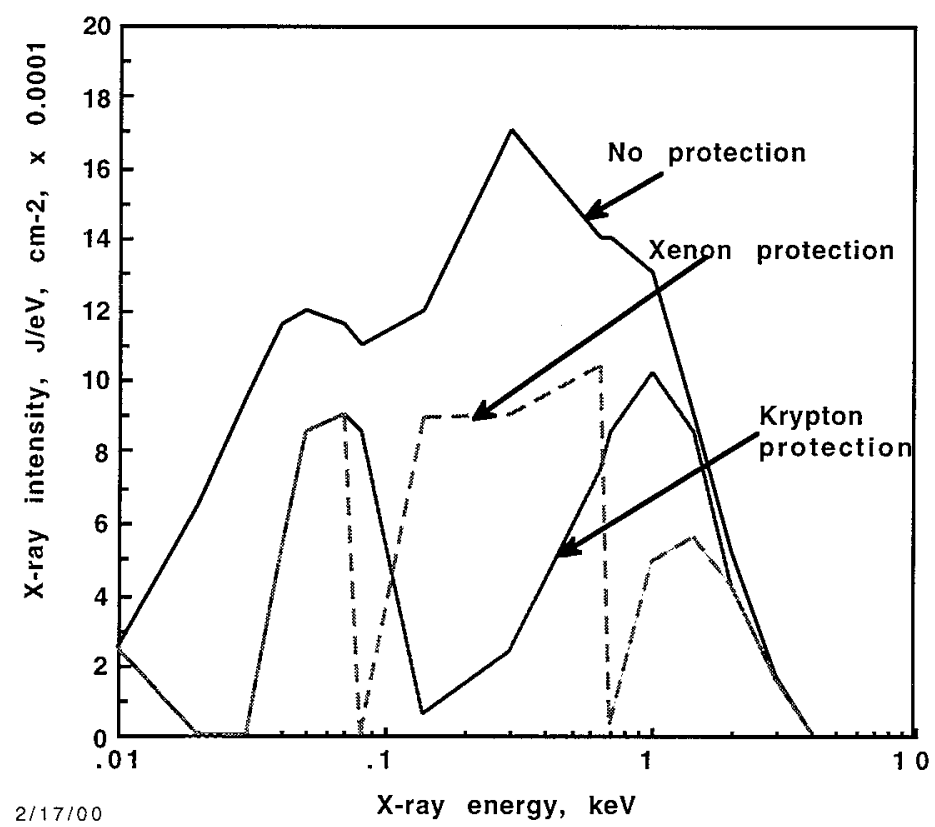

Fig. 6. X-ray intensity at the optics for $20 \mathrm{MJ}$ NIF shots showing the attenuation by xenon and by krypton for line density of $4.9 \times 10^{17} / \mathrm{cm}^{2}$.

and $600 \mathrm{eV}$. Between 700 and $1500 \mathrm{eV}$ Xe is better. $\mathrm{Kr}$ being lighter by a factor of 1.56 would expand somewhat more quickly. Another advantage of $\mathrm{Kr}$ is its lower cost by a factor of 12 . Future investigation with mixtures should determine how much better $\mathrm{x}$-ray attenuation can occurs for the same loss of laser light or how much less laser light can be lost for the same $x$-ray attenuation. A preliminary calculation indicates there was less than $20 \%$ difference in attenuation for mixtures of the same line number density as for pure Xe. Optical damage is absorption dependent, which itself is wavelength dependent, so future calculations need to consider both the wavelength dependencies of the optical material and the gas used.

An important assumption to be checked is whether half the laser light is absorbed by small droplets of liquid Xe. If the absorption is only on the surface of $10 \mu \mathrm{m}$ size droplets rather than throughout the interior, then a more complicated analysis is required. Conversely, if most of the energy is reflected and 
transmitted rather than absorbed, then the calculations will need to be revised. Another assumption needing investigation is how much expansion of the droplet occurs during the four ns intense laser light pulse or the $17 \mathrm{~ns}$ pre-pulse. That is, how much more light is blocked from getting to the target than the geometric area of the liquid droplet? A 5\% loss is probably acceptable to the NIF operations; however, an attempt should be made to reduce this. At present we assume no expansion during the entire laser pulse and assume diffraction makes the droplet $\lambda / 2$ larger in radius $(\lambda=1 / 3 \mu \mathrm{m})$. This assumption needs further study but may be reasonable because during most of the laser pulse the intensity is low and absorption will be low. Absorption being nonlinear becomes large during the short intense part of the pulse. We are only concerned with diffraction of the $1 / 3 \mu \mathrm{m}$ light.

\section{Model and calculations}

The density of droplets $\mathrm{N} / \mathrm{V}$ over a region of thickness $\mathrm{d}$ and droplet radius $\mathrm{r}$ must be such that the laser light absorption fraction is only $\varepsilon$.

$\pi \mathrm{r}^{2}(\mathrm{~N} / \mathrm{V}) \mathrm{d}=\varepsilon$

A typical value for $\varepsilon$ might be 0.05 for $5 \%$ loss of the laser light on the way to the target. The radius $r$ needs to include the original droplet radius plus a half wavelength to account for diffraction plus any expansion due to absorbed light during the laser pulse. The atom line density after evaporation and uniform spreading is given below:

$$
\left(\frac{A}{M}\right) \rho \frac{4}{3} \pi r^{3}\left(\frac{N}{V}\right) d=n d
$$

Here $\mathrm{A}$ is Avagadro's number, $\mathrm{M}$ is the mass number, 131.3 for Xenon, $\rho$ is 3060 $\mathrm{kg} / \mathrm{m}^{3}, \mathrm{n}$ is the gas atom number density, so equations (1) and (2) give $r=\frac{n d}{\frac{4}{3} \varepsilon \frac{A}{M} \rho}$ 
The average space between the droplets is $\mathrm{x}$ :

$$
\begin{aligned}
& \mathrm{x}=(\mathrm{V} / \mathrm{N})^{0.333} \\
& x=\pi^{1 / 3} \frac{d}{\varepsilon}\left[\frac{n}{\frac{4}{3} \frac{A}{M} \rho}\right]^{2 / 3}
\end{aligned}
$$

The fraction of the $\mathrm{x}$ rays passing through the gas is $\exp (-\mathrm{nd} / \mathrm{n} \lambda)=\exp \left(-\mathrm{f}_{\mathrm{mfp}}\right)$

where $f_{m f p}=$ number of mean free paths in the gas for $x$ rays.

\section{Table 1}

Areal density for $1 \mathrm{e}$-folding of $\mathrm{x}$ rays for xenon

\begin{tabular}{|l|l|l|l|}
\hline $\mathrm{E}, \mathrm{keV}$ & $\mathrm{n} \lambda, \mathrm{cm}^{-2}$ & $\rho \lambda, \mathrm{g} / \mathrm{cm}^{2}$ & $\begin{array}{l}\text { Pd,Torr-cm } \\
@ 164 \mathrm{~K}\end{array}$ \\
\hline 1 & $4.885 \times 10^{17}$ & $1.57 \times 10^{-4}$ & 8.2 \\
\hline 1.46 & $1.054 \times 10^{18}$ & $2.29 \times 10^{-4}$ & 12 \\
\hline 2 & $2.38 \times 10^{18}$ & 3.14 & 16.5 \\
\hline 3 & $6.25 \times 10^{18}$ & 4.7 & 4.7 \\
\hline
\end{tabular}

Areal density nd needed for one e-folding attenuation equals $1 / \sigma$, which is equal to $n \lambda$, where $d$ is the gas layer thickness. Then the areal density nd is $\mathrm{nd}=\mathrm{f}_{\mathrm{mfp}} \mathrm{n} \lambda$.

Typical parameters are given in Table 2 . 
Table 2

Typical parameters

\begin{tabular}{|l|l|l|l|l|l|l|l|}
\hline $\begin{array}{l}\mathrm{n}, \\
10^{21} \mathrm{~m}^{-2}\end{array}$ & $\varepsilon$ & $\begin{array}{l}\mathrm{d}, \\
\mathrm{mm}\end{array}$ & $\mathrm{d} / \mathrm{x}$ & $\mathrm{x}, \mathrm{mm}$ & $\mathrm{r}, \mu \mathrm{m}$ & $\begin{array}{l}\text { eV/atom } \\
\text { required }\end{array}$ & $\begin{array}{l}\text { eV/atom } \\
\text { absorbed } \\
\text { Eq. (10) }\end{array}$ \\
\hline 4.89 & 0.05 & 10 & 38 & 0.26 & 5.2 & 6.3 & 4.4 \\
\hline 4.89 & 0.05 & 50 & 110 & 0.44 & 5.2 & 18 & 4.4 \\
\hline 4.89 & 0.05 & 100 & 180 & 0.55 & 5.2 & 29 & 4.4 \\
\hline 48.8 & 0.05 & 10 & 8.3 & 1.2 & 52 & 135 & 0.44 \\
\hline 48.8 & 0.05 & 50 & 25 & 2.0 & 52 & 400 & 0.44 \\
\hline 48.8 & 0.05 & 100 & 39 & 2.6 & 52 & 630 & 0.44 \\
\hline 48.8 & 0.02 & 50 & 9.8 & 5.1 & 130 & 2473 & 0.18 \\
\hline 10.5 & 0.05 & 10 & 23 & 0.43 & 11 & 17 & 2 \\
\hline 105 & 0.05 & 10 & 5 & 1.99 & 112 & 380 & 0.2 \\
\hline 105 & 0.05 & 50 & 15 & 3.4 & 112 & 1100 & 0.2 \\
\hline Power & plant & case & & & & & \\
\hline 48.8 & 0.05 & 10 & 3.8 & 2.6 & 52 & 28 & 0.44 \\
\hline 48.8 & 0.02 & 10 & 1.6 & 6.4 & 130 & 180 & 0.18 \\
\hline
\end{tabular}

The time for evaporated gas to close the gap, $\tau_{\text {close }}$

$\tau_{\text {close }}=0.5 \mathrm{x} / \mathrm{v}$

where $v$ is the average speed of the gas. The energy per atom that is needed for closure is:

$E_{\text {required }}=1 / 2 \mathrm{mv}^{2}=0.5 \mathrm{~m}\left(0.5 \mathrm{x} / \tau_{\text {close }}\right)^{2}$

The energy per atom required for $43 \mathrm{~ns}$ closure time is given in Table 2 with the last two entries for $200 \mathrm{~ns}$ closure time appropriate to a power plant case.

The laser energy absorbed per atom in the gas located at $6 \mathrm{~m}$ is 
$E_{\text {absorbed }}=\frac{f_{\text {absorbed }}\left(\frac{6.75}{6.0}\right)^{2}\left(10.85 \mathrm{~J} / \mathrm{cm}^{2}\right) \pi r^{2}}{\frac{4}{3} \frac{A}{M} \rho \pi r^{3}}$

where $f_{\text {absorbed }}$ is the fraction of light absorbed in the droplet, which we assume to be 0.5 and the intensity at the blast shield in the NIF is $10.85 \mathrm{~J} / \mathrm{cm}^{2}$.

The energy in the laser light is $6.5 \mathrm{~J} / \mathrm{cm}^{2}$ at $1 \omega$ light $(1 \mu \mathrm{m}), 1.1 \mathrm{~J} / \mathrm{cm}^{2}$ at

$2 \omega(0.5 \mu \mathrm{m})$, and $3.25 \mathrm{~J} / \mathrm{cm}^{2}$ at $3 \omega(0.33 \mu \mathrm{m})$ at $6.75 \mathrm{~m}$ from the target, which is the location of the last optics.

$E_{\text {absorbed }}=\frac{0.5\left(\frac{6.75}{6}\right)^{2} 10.85 \mathrm{~J} \cdot 10^{4}}{\frac{6.02}{131} \cdot 10^{23} 3060 \cdot 10^{3} \frac{4}{3} r 1.6 \cdot 10^{-19} \mathrm{~J} / \mathrm{eV}}=\frac{2.29 \cdot 10^{-5} \mathrm{eV} / \text { atom }}{r}$

This calculated absorbed energy per atom is given in Table 2. Typically, the absorption results in a few $\mathrm{eV}$ per atom and thermal speeds of $\sim 2000 \mathrm{~m} / \mathrm{s}$. When there is sufficient energy absorbed to cause the interspace to fill, our model predicts $x$-ray attenuation will result. Even if the expanding vapor cloud does not fill the interspace completely, good x-ray attenuation will still result as discussed next.

\section{Improved attenuation model}

Up to this point the assumption has been made that the droplets must be vaporized and the vapor must expand to half the inter-droplet spacing for good $x$-ray attenuation. This is an unnecessary assumption because the droplet clouds can shadow each other and thereby offer good attenuation even when the expansion is far from complete. We calculated the opacity $\eta$ for each planar row shown in Fig. 7 containing expanding droplets. We assumed that each of $\mathrm{N}$ rows spaced $x$ apart was randomized relative to shadowing, giving a combined opacity $\mathcal{E}$.

$\varepsilon=1-(1-\eta)^{N}$ 
$\eta=\frac{2 \pi}{x^{2}} \int_{0}^{a} r d r\left(1-e^{-\frac{2\left(a^{2}-r^{2}\right)^{1 / 2} / 20 a_{0}^{3} \sigma}{a^{3}}}\right)$

where $\mathrm{n}_{0}$ is liquid density of $\mathrm{Xe}\left(1.6 \times 10^{22} \mathrm{~cm}^{-3}\right), 1 / \sigma$ is $1.05 \times 10^{18} \mathrm{~cm}^{-2}, \mathrm{a}_{0}$ is the liquid droplet radius and $x$ is the droplet spacing in each row. The transmission is $1-\varepsilon$. The results of numerically integrated of Eq. 12 are shown in Fig. 8. Early in the expansion phase, we have, $\eta=\pi \mathrm{a}^{2} / \mathrm{x}^{2}$ and $\mathrm{a}$ is near $\mathrm{a}_{0}$. For the $11 \mu \mathrm{m}$ droplets spaced at $429 \mu \mathrm{m}$, the attenuation saturates at 60 to $70 \mu \mathrm{m}$ rather than the interhalf space of $215 \mu \mathrm{m}$, because the likelihood of the laser light finding any space between the expanding clouds in all droplet rows is small. This means that much less time is needed for expansion. Hence, we can have larger droplets spaced further apart with less interference with the laser light. The laser absorption fraction $\mathrm{f}_{\text {absorbed }}$ may therefore be less than $5 \%$. We need not worry about the early part of the laser pulse (foot pulse) causing much expansion because the energy content is low and the absorption requires a multi-photon process to get it started. However, using the expected time dependence of the laser pulse we could calculate the time dependent expansion to see how much of the laser pulse is blocked due to early expansion.

The values of the energy per atom required to fill the interspace (Table 2) is often much more than the energy absorbed per atom. This averaging due to shadowing makes a large required energy still acceptable. More study could elucidate the actual required energy. 


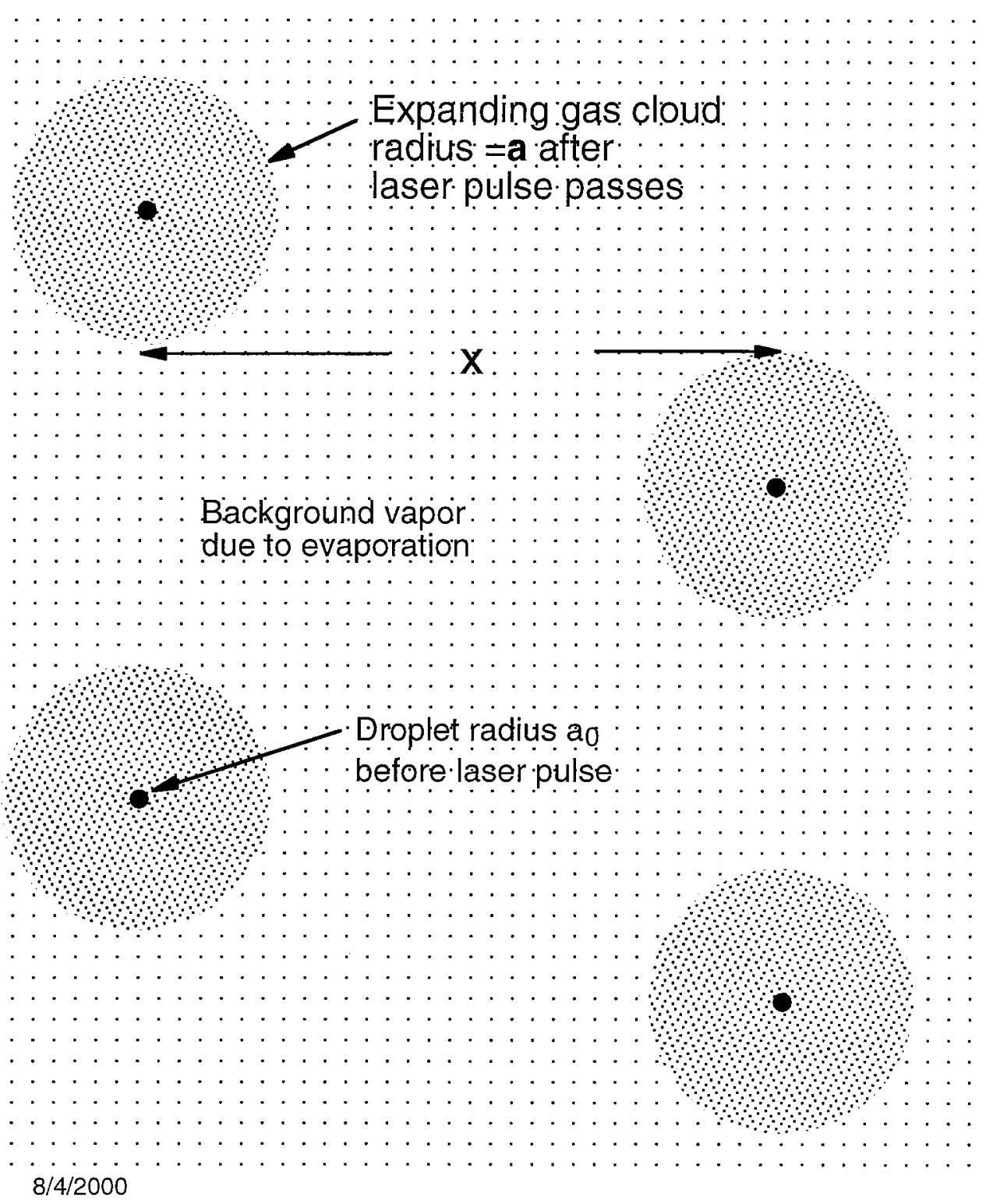

Fig. 7. The droplets are shown along with the expanding gas cloud that occurs later. 


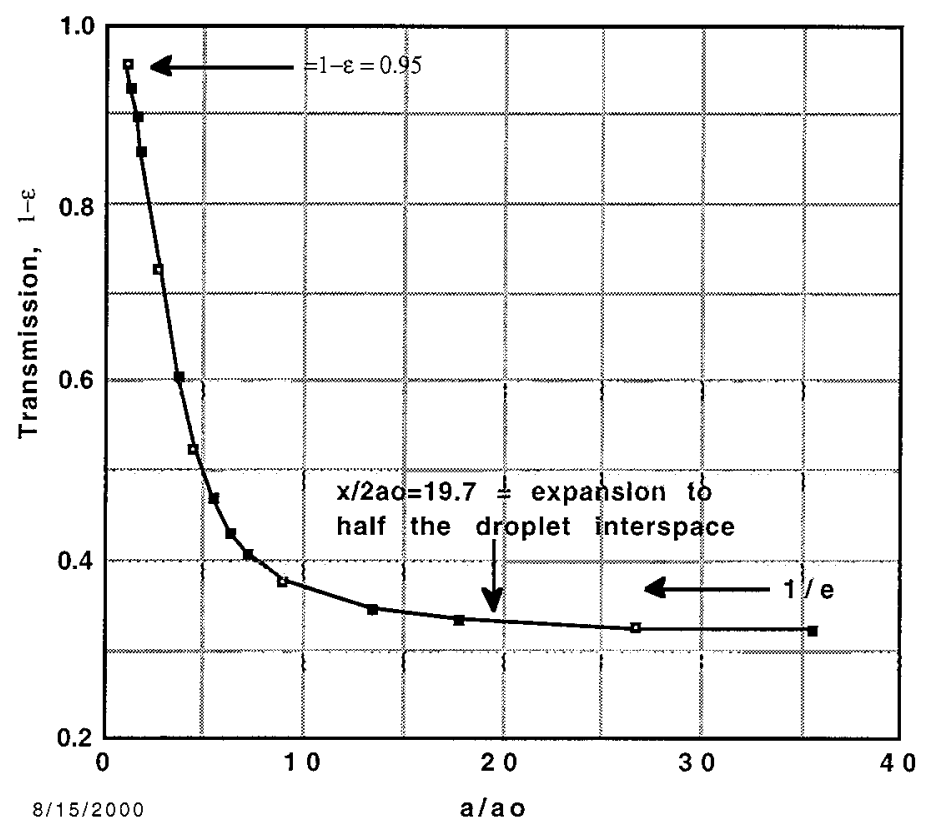

Fig. 8. $\mathrm{X}$ ray transmission of the cloud of droplets decrease as the droplets expands with time. Notice that the estimate of transmission for large radius saturates a little less than the one e-folding of uniform gas after the expanded droplets merge, which indicates the accuracy of the analysis.

\section{Example designs}

In case 1 , the xenon density is chosen to be one mean free path at $1 \mathrm{keV}$ photon energy with $5 \%$ laser light lost. A $50 \mathrm{~mm}$ thick zone of droplets is assumed in front of the optics with a spacing of $0.44 \mathrm{~mm}$ between droplets and $5.2 \mu \mathrm{m}$ radius droplets. A zone thickness of $50 \mathrm{~mm}$ amounts to 110 rows of droplets.

In case 2, the xenon density is chosen to be one mean free path at $1.0 \mathrm{keV}$ photon energy with $5 \%$ light lost. A $10 \mathrm{~mm}$ thick zone of droplets is assumed in front of the optics with a spacing of $0.26 \mathrm{~mm}$ and $5.2 \mu \mathrm{m}$ radius droplets. A $10 \mathrm{~mm}$ zone thickness amounts to 38 droplets. In both cases the droplets vaporize and fill the interspace by the time most of the $\mathrm{x}$ rays try to pass through the gas zone. 
In case 3, the xenon density is chosen to be one mean free path at $1.46 \mathrm{keV}$ photon energy with $5 \%$ light lost. A $10 \mathrm{~mm}$ thick zone of droplets is assumed in front of the optics with a spacing of $0.43 \mathrm{~mm}$ and $11 \mu \mathrm{m}$ radius droplets, which amounts to 23 droplets. The advantage of this case is its lower absorbed energy of heated Xe atoms ( $2 \mathrm{eV} /$ atom), which will not fully expand to fill the interspace but should still give adequate average attenuation. More study is recommended to chose the parameters.

\section{Nozzle array}

A nozzle array (Fig. 9) could inject xenon droplets much like a shower head. It could be pulsed on only until the droplets have traveled about $38 \mathrm{~cm}$ and then turned off. The array parameters for the two example cases are given below:

Case 1-Nozzle plate $50 \mathrm{~mm}$ by $380 \mathrm{~mm}$ with droplets spaced $0.44 \mathrm{~mm}$ apart, droplet radius $5.2 \mu \mathrm{m}$. There are 100,000 individual droplet orifices!

Case 2-Nozzle plate $10 \mathrm{~mm}$ by $380 \mathrm{~mm}$ with droplets spaced $0.26 \mathrm{~mm}$ apart, droplet radius $5.2 \mu \mathrm{m}$. There are 60,000 individual orifices.

Case 3-Nozzle plate $10 \mathrm{~mm}$ by $380 \mathrm{~mm}$ with droplets spaced $0.43 \mathrm{~mm}$ apart, droplet radius $11 \mu \mathrm{m}$. There are 20,000 individual orifices.

We need a stream of droplets $380 \mathrm{~mm}$ long from each hole in the nozzle plate with a spacing between droplets of $0.2 \mathrm{~mm}$ or more. After the stream of droplets reaches $380 \mathrm{~mm}$ they are turned off. This is a pulsed system used only once every few hours for the NIF. 
Cryogenic liquid droplets have been made as described in Ref. 6 and shown in Fig. 9. The small holes or orifices are made by photo-etching a mask. Plugging due to freezing will have to be avoided.

Table 3

Droplet generator parameters sized to protect one $38 \times 38 \mathrm{~cm}$ fused $\mathrm{SiO}_{2}$ slab

(10 $\mathrm{mm} \times 380 \mathrm{~mm})$

\begin{tabular}{|l|l|l|l|l|l|}
\hline & $\begin{array}{l}\text { droplet } \\
\text { radius, } \mu \mathrm{m}\end{array}$ & $\begin{array}{l}\text { droplet } \\
\text { spacing, } \mathrm{mm}\end{array}$ & $\begin{array}{l}\text { holes per } \\
\text { optical unit }\end{array}$ & $\begin{array}{l}\text { laser light } \\
\text { lost }\end{array}$ & $\begin{array}{l}\text { energy per } \\
\text { Xe atom, } \mathrm{eV}\end{array}$ \\
\hline $\begin{array}{l}\text { X-ray } \\
\text { attenuator }\end{array}$ & 11 & 0.43 & 20,000 & $5 \%$ & 2 \\
\hline $\begin{array}{l}\text { Target debris } \\
\text { attenuator }\end{array}$ & 36 & 10 & 24 & $0.001 \%$ & 0.6 \\
\hline
\end{tabular}

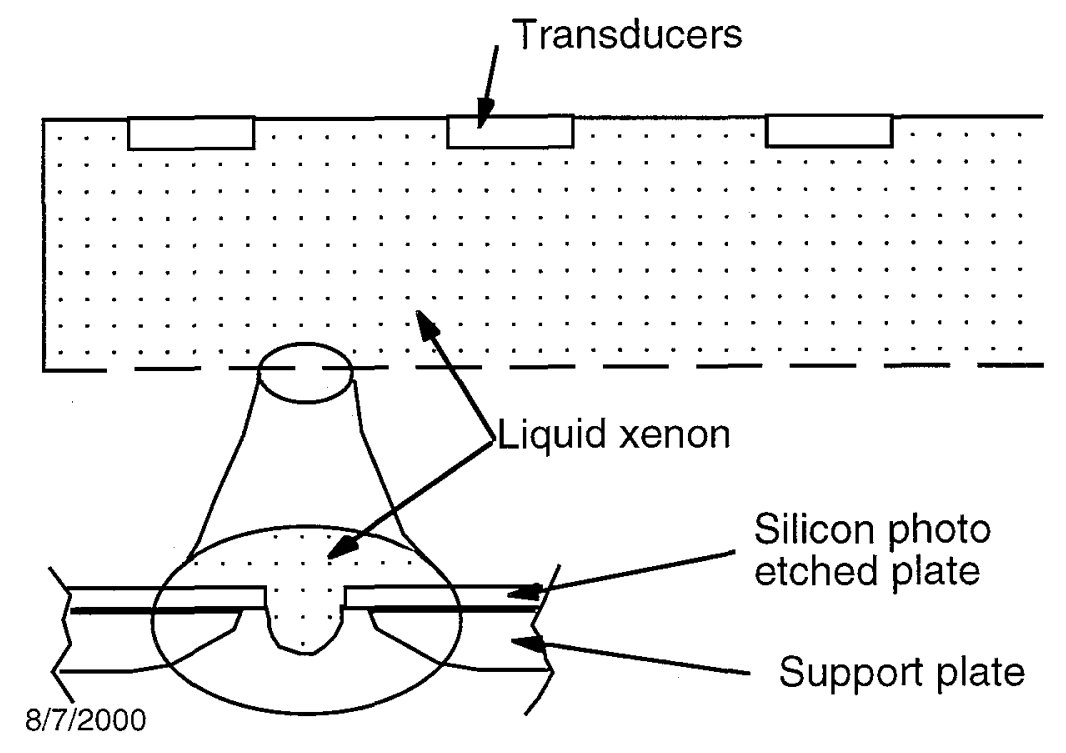

Fig. 9. A cryogenic xenon or krypton droplet generator. 
The static pressure of the liquid must be kept below the surface tension produced pressure. $\mathrm{P}_{\text {surface tension }}=2 \mathrm{~S} / \mathrm{r}=2 \times 0.019 / 11.1 \mu \mathrm{m}=3400 \mathrm{~Pa}(0.05 \mathrm{psi})$. For $3 \mathrm{~m} / \mathrm{s}$ droplets, the pressure the transducers must generate is $\mathrm{P}=1 / 2 \rho v^{2}=1 / 2 \times 35403^{2}=$ $13500 \mathrm{~Pa} \mathrm{(2} \mathrm{psi)} \mathrm{as} \mathrm{shown} \mathrm{in} \mathrm{Fig.} \mathrm{10.} \mathrm{To} \mathrm{avoid} \mathrm{bulk} \mathrm{boiling,} \mathrm{the} \mathrm{vapor} \mathrm{pressure}$ should be kept below the surface tension pressure of $3400 \mathrm{~Pa}$ in the example above. This may be a problem as the pressure at the freezing point at $160 \mathrm{~K}$ is 74 $\mathrm{kPa}$ and the temperature must be below $130 \mathrm{~K}$ to get the pressure below $3.4 \mathrm{kPa}$. Reversing the orientation in Fig. 9 will allow gravity to help avoid the extrusion of liquid between pulses.

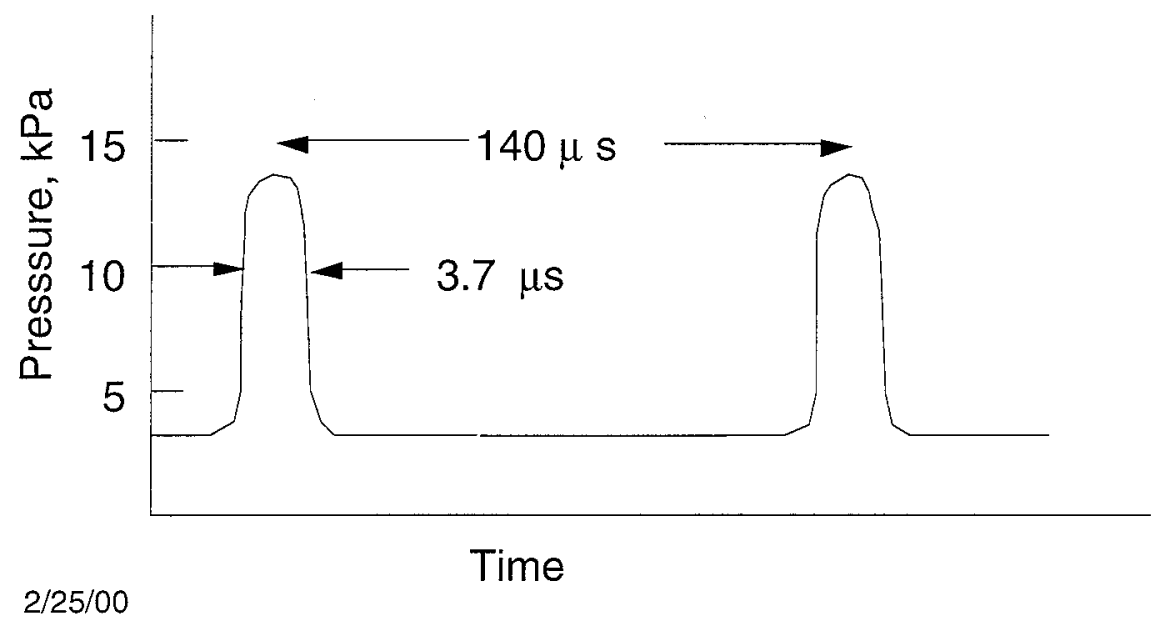

Fig. 10. The pressure time sequence for $3 \mathrm{~m} / \mathrm{s}$ droplets to produce $11 \mu \mathrm{m}$ radius droplets spaced every $0.43 \mathrm{~mm}$.

During the $17 \mathrm{~ns}$ pre-pulse, sound can travel $17 \mu \mathrm{m}$. During the $2 \mathrm{~ns}$ intense laser pulse sound can travel $2 \mu \mathrm{m}$. During the $40 \mathrm{~ns}$ for the first $\mathrm{x}$ rays to arrive at the gas layer sound can travel $40 \mu \mathrm{m}$ into the liquid. The time it takes heat to travel to the center of a droplet is $(5.2 \mu \mathrm{m})^{2} / \alpha=200 \mu \mathrm{s}$ and $(11 \mu \mathrm{m})^{2} / \alpha=850 \mu \mathrm{s}$. Clearly conduction heat transfer into the interior of the droplet is negligible during times of interest. The isochorically heated droplet should fracture as well as vaporize. 
The spallation speed from isochoric heating is estimated at $2000 \mathrm{~m} / \mathrm{s}$ which is enough to expand and fill the inter-droplet spacing (half of $0.2 \mathrm{~mm}$ ) in $40 \mathrm{~ns}$.

\section{Stopping power for vaporized target debris}

The stopping power of the vaporized target debris by the xenon gas layer can be judged by looking at the respective line densities. The target hohlraum in the NIF is about $30 \mu \mathrm{m}$ of Au which is $0.06 \mathrm{~g} / \mathrm{cm}^{2}$ on average at $3 \mathrm{~mm}$ radius $(30 \mu \mathrm{m} x$ $19.3 \mathrm{~g} / \mathrm{cm}^{3}$ ). Upon vaporization and expansion to $6 \mathrm{~m}$ this becomes $1.5 \times 10^{-8}$ $\mathrm{g} / \mathrm{cm}^{2},\left[0.058 \mathrm{~g} / \mathrm{cm}^{2}(3 \mathrm{~mm} / 6 \mathrm{~m})^{2}\right]$. This is to be compared to the xenon line density of $2 \times 10^{-4} \mathrm{~g} / \mathrm{cm}^{2}$. The xenon can hence easily stop hohlraum vapor debris with orders of magnitude to spare. Incidentally, shrapnel should not come from the hohlraum, because there is enough energy to vaporize it completely, except for "dud" shots. Liquefied or solid hohlraum support "chunks" can in principle be blocked by line of sight shielding, since the supports are not in the laser line of sight.

Some vaporized target debris might condense into droplets during the in-flight expansion-cooling phase. Using the over simplified stopping principle of equal mass (equal column density: Fermi's law) being swept out for good stopping ( $\rho_{\text {condensed debris }} 4 / 3 r<(\rho l)_{\text {gas }}$ ), we can estimate the size of droplets stopped by the same xenon gas used to stop $x$ rays as $2 \times 10^{-4} \mathrm{~g} / \mathrm{cm}^{2}$ or $\left(1 \times 10^{18} \mathrm{~cm}^{-2}\right)$. For hohlraum material of density of $15,000 \mathrm{~kg} / \mathrm{m}^{3}$, droplets of less than $0.1 \mu \mathrm{m}$ are stopped in the gas. Since the debris is moving slowly, a much higher gas density can be provided to stop larger droplets. Perhaps droplets as large as $10 \mu \mathrm{m}$ radius can be stopped with practical droplet systems.

\section{Cost of xenon and krypton}


Xenon cost quotes are $\$ 9.00 /$ liter @ $5.44 \mathrm{~g} /$ liter in 1000 liter bottles, which is $\$ 1.65 / \mathrm{g}$. In example case 3 where the gas is one e-folding thick at $1.46 \mathrm{keV}$ or 2.3 $\times 10^{-4} \mathrm{~g} / \mathrm{cm}^{2}$, the amount of gas needed for coverage of 192 optical shields of 38 $\mathrm{cm}$ by $38 \mathrm{~cm}$ square is:

$2.3 \times 10^{-4} \mathrm{~g} / \mathrm{cm}^{2} \times 38 \mathrm{~cm} \times 38 \mathrm{~cm}=0.33 \mathrm{~g} /$ optics

$0.28 \mathrm{~g} \times 192 \times$ factor of two wastage $=127 \mathrm{~g} / \mathrm{shot}$

$127 \mathrm{~g} \times \$ 1.65 / \mathrm{g}=\$ 210 / \mathrm{shot}$

This cost would be acceptable for the NIF to protect optics that otherwise might be destroyed on each shot and cost of order $\$ 0.1 \mathrm{M}$ to replace. For power plants the xenon would have to be recovered and recycled for cost reasons as only a few cents per shot can be spent on optics protection. The xenon could be pumped and recycled even for the NIF. For a power plant, a one day supply of xenon might be $(6$ shots $/ \mathrm{s} \times 210 \$ /$ shot $\times 3600 \times 24 \mathrm{~s} / \mathrm{d}=109$ million $)=\$ 109 \mathrm{M} / \mathrm{d}$ or $\$ 4.5 \mathrm{M} / \mathrm{hr}$.

Purchase of large quantities of xenon would result in economies that would lower these estimates. Use of $\mathrm{Kr}$ at $\$ 0.48 /$ liter in 1000 liter bottles or $\$ 0.14 / \mathrm{g}$ would lower these costs by a factor of 12 . For power plants the energy penalty to liquefy the $\mathrm{Xe}$ or $\mathrm{Kr}$ is small compared to the fusion yield.

Table 4

Xenon and krypton properties in liquid state, ${ }^{131.3} \mathrm{Xe}_{54}$ and ${ }^{83.8} \mathrm{Kr}_{36}$

\begin{tabular}{|l|l|l|}
\hline & Xe & $\mathrm{Kr}$ \\
\hline Abundance in air & $0.1 \mathrm{ppm}$ & $1.1 \mathrm{ppm}$ \\
\hline sound speed & guess $1000 \mathrm{~m} / \mathrm{s}$ & \\
\hline$\rho$ & $3060 \mathrm{~kg} / \mathrm{m}^{3} @ 164 \mathrm{~K}$ & 2420 \\
\hline $\mathrm{k}$ & $0.069 \mathrm{~W} / \mathrm{mK}$ & \\
\hline $\mathrm{C}_{\mathrm{p}}$ & $160 \mathrm{~J} / \mathrm{kgK}$ & 248 \\
\hline$\alpha=\mathrm{k} / \rho \mathrm{C}_{\mathrm{p}}$ & $1.41 \times 10^{-7} \mathrm{~m}^{2} / \mathrm{s} ;$ & \\
$\alpha=$ thermal diffusivity & $\tau=\mathrm{r}^{2} / \alpha$ & \\
\hline
\end{tabular}




\begin{tabular}{|l|l|l|}
\hline Surface tension & $0.0187 \mathrm{~J} / \mathrm{m}^{2} @ 162 \mathrm{~K}$ & \\
\hline $\mathrm{T}_{\text {melt }}$ & 161.1 & 116.4 \\
\hline $\mathrm{T}_{\text {boil }} @ 760$ Torr & $164 \mathrm{~K}$ & $121 \mathrm{~K}$ \\
\hline Heat of vaporization & $96 \mathrm{~kJ} / \mathrm{kg}$ & 108 \\
\hline Heat of melting & $14 \mathrm{k} / \mathrm{kg}$ & 16 \\
\hline
\end{tabular}

\section{Conclusion}

A preliminary look at the idea of $x$ ray protection of final optics using xenon or krypton droplets looks promising. The loss due to diffraction and refraction on the early expansion of the droplet must be checked to see how much more than the assumed $5 \%$ of the laser light does not get to the target. The laser absorption in the liquid droplet is a key feature to be examined more closely. The droplet configuration can be made with well know techniques. Making the droplets will be challenging, however, so further study is required, but it looks well within the state of the art. A droplet generator design and costing will be needed if this protection concept is to be pursued.

\section{Acknowledgements}

This work was performed under the auspices of the U.S. Department of Energy by University of California Lawrence Livermore National Laboratory under contract No. W-7405-Eng-48. Andy Anderson supplied numerous data pertaining to the NIF conditions quoted including laser light intensities, $x$-ray intensities and timing. Discussions are gratefully acknowledged with Mike Feit, Charles Orth, Alex Rubenchik, and David Eder at LLNL and with Min Chen at MIT, and Al Pisano at UC Berkeley.

\section{References}


1. R. W. Moir, "Protection of final optics with cryogenic liquid droplets," Thirteenth International Conference on laser interactions and related plasma phenomena, April 13-18, 1997, Monterey, California.

2. L. M. Waganer, "Innovation lead the way to attractive inertial fusion energy reactors-Prometheus-L and Prometheus-H," Fus. Eng. and Design 25 (1994) 125-143.

3. Mike Feit and Alex Rubenchik, Lawrence Livermore National Laboratory, Private communication (1996).

4. Min Chen, MIT, private communications (1996).

5. Andrew T. Anderson, " $X$-ray ablation measurements and modeling for ICF applications," Lawrence Livermore National Laboratory report UCRL-LR125352 (1996).

6. M. J. Gouge and P. W. Fisher, "A cryogenic xenon droplet generator for use in a compact laser plasma x-ray source," Rev. Sci. Instrum., 68 (1997) 2158-2162. 